\title{
Contraception for adolescents with disabilities: taking control of periods, cycles and conditions
}

\author{
Jane Dickson, ${ }^{1}$ Annette Thwaites, ${ }^{2}$ Lesley Bacon ${ }^{1}$
}

${ }^{1}$ Contraception and Sexual Health, Oxleas NHS Foundation Trust, London, UK

${ }^{2}$ Contraception and Sexual health, Oxleas NHS Foundation Trust, Lewisham and Greenwich NHS Trust, London, UK

\section{Correspondence to}

Dr Jane Dickson, Contraception and Sexual Health, Oxleas NHS Foundation Trust, Market Street Health Centre, London SE18 6QR, UK; jane.dickson@nhs.net

Received 31 January 2017 Revised 16 July 2017 Accepted 10 August 2017 Published Online First 8 November 2017

\section{Linked}

- http://dx.doi.org/10.1136/ bmjsrh-2017-200019

- http://dx.doi.org/10.1136/ bmjsrh-2017-200020

CrossMark

To cite: Dickson J, Thwaites A, Bacon L. BMJ Sex Reprod Health 2018;44:7-13.

\begin{abstract}
The onset of puberty, periods and sexual relationships can be difficult for adolescents and parents. Adolescents with disabilities face a wide range of additional challenges (physical, mental, social and intellectual), which may impact the quality of their lives and those of their families and carers. Research on the use of contraception in young women with disabilities is limited, and clinicians have little practical guidance for best practice. This review article aims to summarise and assess the evidence and guidance for the use of contraception in this group, particularly with regard to management of menstrual and cyclical problems. Multidisciplinary teamwork is important for recognising and addressing the concerns of patients and their carers effectively. The legal and ethical considerations are also highlighted here, as this group of adolescents is highly vulnerable to sexual exploitation and abuse.
\end{abstract}

\section{LITERATURE METHODOLOGY}

The Cochrane Library was searched for relevant studies and articles using the keywords 'contraception', 'adolescent' and 'disability'. Only one relevant large American survey on the sexual behaviour of adolescents with chronic disease and disability ${ }^{1}$ was found. The same search criteria were used on the PubMed database, which produced 133 search results, which were screened for relevance. This demonstrates the limited amount of evidence published on this topic, and where specific evidence is lacking, generic guidance has been adapted here based on the authors' (JD and LB) experience and practice.

\section{INTRODUCTION}

Menarche in adolescents with disabilities can cause significant distress and disruption to their lives and the lives of those

\section{Key message points}

Adolescents with chronic medical conditions are as likely to need contraception as their peers. Safeguarding risk assessments are especially important.

- Adolescents with physical and learning disabilities may require management of 'normal' menstruation in order to improve their quality of life.

- Hormonal contraception is effective for the management of many gynaecological problems in adolescents with disabilities, and the usual contraindications to contraceptive use may not apply.

living with and caring for them. The timing of puberty and menarche, the nature of periods and a patient's ability to cope with them can all be affected by a wide range of conditions. Conversely, menstruation can also exacerbate symptoms of some medical conditions and there is potential for contraceptive hormonal methods to be used to good effect. Adolescents with chronic conditions are as likely to be sexually active as their peers, and significantly more likely to have been sexually abused. ${ }^{1}$ Robust safeguarding risk assessments are therefore required. This review aims to present and assess the evidence for the use of contraceptive methods in this group, highlighting key common principles, legal and ethical concerns, and practical tips for clinicians involved in their care.

\section{ANTICIPATING PROBLEMS: PUBERTY AND THE MENARCHE Puberty}

In order to be able to provide support, clinicians should be familiar with the 
progression of puberty, which usually follows a set pattern. Tanner described physical features in the 1960s and $1970 \mathrm{~s}^{2}$ (see table 1). Normally breast development begins at around age 10, followed by pubic hair 6 months later. There is then a growth spurt. Following this, Tanner Stage 4 pubic hair and Stage 3-4 breast development occurs, and these usually immediately precede menstruation. Menstruation is closely related to bone age and the average age for the menarche is between 12 years 10 months and 13 years.

Depending on the nature of any disability, puberty and menarche may be timed early, normally or late. Advances in medicine have resulted in increased survival of children with disabilities into puberty and beyond, and with this comes a continuing challenge to meet their specific needs. The timing of puberty and menstruation is multifactorial and any chronic condition or systemic disease can impair development and delay menstruation. Treatment of systemic disease can often resolve or improve the situation. Earlier sexual development may occur when there are neurodevelopmental disabilities (eg, cerebral palsy) and sometimes there is a delay in puberty in some girls with autistic spectrum disorders. ${ }^{3}$

\section{Menarche}

The median age at menarche has remained relatively stable in developed countries, where $98 \%$ of girls will have had a period by the age of 15 years. ${ }^{4}$ Primary amenorrhoea with absence of development of secondary sexual characteristics should be investigated at age 14 years and, in the presence of secondary sexual characteristics, it should be investigated at age 16 years. ${ }^{5}$ Early menarche is associated with a range of conditions in which the hypothalamic-pituitary-gonadal axis is prematurely activated and/or the levels of gonadal steroids are raised. In these scenarios, careful consideration should be given to the social consequences for patients such as difficulties with peers and alarm within families. Clinicians should be prepared to provide information and support prior to onset of menses as carers may already be apprehensive about the consequences. ${ }^{6-8}$

\begin{tabular}{lll}
\hline $\begin{array}{l}\text { Table } 1 \\
\text { girls }\end{array}$ & Tanner staging of physical development in adolescent \\
\hline Stage & Pubic hair & Breast development \\
\hline 1 & Prepuberty & Prepuberty \\
\hline 2 & $\begin{array}{l}\text { Narrow border along the } \\
\text { labia majora }\end{array}$ & $\begin{array}{l}\text { Small mound and areola starts } \\
\text { to grow }\end{array}$ \\
\hline 3 & $\begin{array}{l}\text { Becoming darker and } \\
\text { more curly, spreading to } \\
\text { mons pubis }\end{array}$ & $\begin{array}{l}\text { Further increase and loss of } \\
\text { contour of separation between } \\
\text { breast and areola }\end{array}$ \\
\hline 4 & $\begin{array}{l}\text { Increasing but still just at } \\
\text { mons pubis }\end{array}$ & $\begin{array}{l}\text { Areola and nipple form } \\
\text { secondary mound }\end{array}$ \\
\hline 5 & $\begin{array}{l}\text { Spreads to adult female } \\
\text { triangle pattern }\end{array}$ & Adult breast appearance \\
\hline
\end{tabular}

MENSTRUAL CYCLE AND DISABILITY

Menstrual patterns may reflect the overall picture of health. It is therefore important for both adolescents and clinicians to understand the range of 'normal' patterns of menstruation, especially in the early years post-menarche. ${ }^{4}$ Charting a menstrual cycle is often helpful, and modern technology such as menstrual apps (eg, Clue ${ }^{\circledR}$ ) can be utilised for more accurate assessment. Assessment can be particularly challenging if there is cognitive impairment and/or multiple carers. Menstruation can exacerbate symptoms of coexistent medical conditions. For example, seizure disorders and epilepsy, which are more common in people with learning difficulties, may heighten either premenstrually or during periods. ${ }^{9}$

Menstrual disorders are common in adolescence and, in the context of disability, heavy menstrual bleeding (HMB) and dysmenorrhoea can be particularly distressing. Approximately 1 in 10 adolescent girls will require treatment for HMB..$^{5}$ Initial investigations include assessment of anaemia and a clotting profile where there are other symptoms, such as excessive bruising, suggestive of a bleeding disorder (eg, Von Willebrand disease). Specific conditions such as hypothyroidism may contribute to heavy bleeding and this may often be the contributing factor for young women with Down's syndrome who experience heavy periods. ${ }^{10}$ Pregnancy and sexually transmitted infections (STIs) should be excluded.

Vaginal examination is not usually required as it is unlikely to add value to the assessment. Where vaginal examinations and/or ultrasound scanning are indicated (eg, when anatomical abnormality needs to be excluded) consent must be sought and additional practical measures or equipment (eg, hoists) may be required. Transabdominal scanning rather than transvaginal scanning will often be more appropriate if ultrasound examination is necessary.

Dysmenorrhoea is also common and may be difficult to elicit in girls with cognitive disabilities. It is important to consider the possibility of first presentation of endometriosis, particularly where pain is unresponsive to treatment. Other conditions to consider are anatomical abnormalities, pregnancy and STIs. It may be necessary to liaise with local laboratories to request chlamydia/gonorrhoea nucleic acid amplification testing using a urine sample if it is not possible to obtain a vulvo-vaginal swab. This is not suitable if the girl is catheterised.

Adolescents with physical and learning disabilities may also require management of 'normal' menstruation due to difficulties with menstrual hygiene, cyclical behaviour change or inappropriate behaviour. Selfcare may be difficult in girls with decreased mobility or bladder and bowel incontinence. Soiling with menstrual blood can lead to a 'triple-incontinence' effect with associated skin breakdown and serial infections. Cyclical mood and behavioural disturbance such 
Table 2 Comparison of contraceptive methods in young women with disabilities

\begin{tabular}{|c|c|c|c|c|c|c|c|}
\hline $\begin{array}{l}\text { Interacting } \\
\text { factor }\end{array}$ & $\mathrm{COC}$ & CTP & $\begin{array}{l}\text { POP } \\
\text { desogestrel }\end{array}$ & $\begin{array}{l}\text { POP } \\
\text { conventional }\end{array}$ & Implant & POI & IUS \\
\hline $\begin{array}{l}\text { Affected by } \\
\text { reduced mobility }\end{array}$ & $\begin{array}{l}\text { May increase VTE } \\
\text { risk }\end{array}$ & $\begin{array}{l}\text { May increase VTE } \\
\text { risk }\end{array}$ & No & No & No & $\begin{array}{l}\text { May increase } \\
\text { osteoporosis risk }\end{array}$ & $\begin{array}{l}\text { Technicalities } \\
\text { of insertion }\end{array}$ \\
\hline $\begin{array}{l}\text { Affected by body } \\
\text { mass index }\end{array}$ & $\begin{array}{l}\text { If raised may } \\
\text { increase VTE risk }\end{array}$ & $\begin{array}{l}\text { If raised may } \\
\text { increase VTE risk }\end{array}$ & No & No & No & $\begin{array}{l}\text { If low may } \\
\text { increase } \\
\text { osteoporosis risk }\end{array}$ & $\begin{array}{l}\text { Technicalities } \\
\text { of insertion }\end{array}$ \\
\hline $\begin{array}{l}\text { Enzyme-inducing } \\
\text { medication }\end{array}$ & May affect & May affect & May affect & May affect & May affect & No effect & No effect \\
\hline $\begin{array}{l}\text { Likelihood of } \\
\text { amenorrhoea }\end{array}$ & $\begin{array}{l}\text { Variable/Increased } \\
\text { if tailored regimen }\end{array}$ & $\begin{array}{l}\text { Variable/Increased } \\
\text { if tailored regimen }\end{array}$ & $\begin{array}{l}\text { Moderate/ } \\
\text { low }\end{array}$ & Low & Moderate & Good & Good \\
\hline
\end{tabular}

as agitation, aggression, tearfulness, depression and self-harm are frequently reported, ${ }^{6}{ }^{11}$ as is antisocial behaviour such as hiding of used sanitary products. These additional factors contribute to stress for families and carers, and menstrual control can become extremely important for quality of life.

\section{USE OF CONTRACEPTION FOR MENSTRUAL CONTROL}

While there are multiple different options available to help manage menstrual conditions, cyclical manipulation with hormonal contraceptive formulations will often give the best outcomes in young people. Non-steroidal anti-inflammatory drugs (eg, mefenamic acid) may reduce pain and flow (it may reduce bleeding by $30-40 \%$ ) but do not have the ability to manipulate the menstrual cycle. ${ }^{12}$ Contraception may be used to stop periods entirely or at least reduce their frequency. The additional advantage of this is that cycle-related symptoms such as mood disturbance, behavioural disturbance and fit exacerbation may also be improved. Age should not be considered a barrier to the use of contraceptive medication for menstrual control and it is important to remember that the UK Medical Eligibility Criteria, ${ }^{13}$ which outline safety considerations of each method, apply when a method is used for contraception, rather than to manage a medical indication.

There are several important aspects to consider before deciding on which option might be the most appropriate. These include:

- Desired outcome (eg, amenorrhoea)

- Mobility

Body mass index (BMI)

- Nature of coexisting medical conditions

- Ability to swallow/use of a feeding tube

- Interacting medication

- Mental capacity

- Consent issues - often it is the child's assent and parental consent that need to be sought

- Difficulty recognising or communicating side effects

- Compliance.
Each hormonal method of contraception is reviewed in turn with key aspects for comparison of hormonal methods of contraception summarised (see table 2). The contraceptive ring is not discussed due to the ethical considerations associated with invasive, monthly vaginal insertions. However, this may be considered when factors involving vaginal self-administration are not problematic.

\section{Combined pill}

Combined oral contraception (COC) is often the initial choice for hormonal manipulation of cycles. It may be very acceptable to a young woman, as her peers may be known to use it. COC reduces menstrual pain and flow, and when taken in a conventional pattern (with a 1-week pill-free interval) periods appear regular. In conditions that are exacerbated during bleeding or with dysmenorrhoea, it may be advantageous to minimise bleeding by taking pills in a tailored manner (ie, taking pills back-to-back and taking a pill-free week when there is sustained bleeding). ${ }^{14}$ No particular monophasic pill is especially useful for this, but phased pills are not suitable. Scheduled breaks every 3-4 months may be helpful to reduce the possibility of breakthrough bleeding ${ }^{3}$ as an alternative to the 'tailored approach'. Amenorrhoea may be achieved in up to $62 \%$ cases of continuous pill-taking. ${ }^{3}$ However, as the COC does not always reliably lead to amenorrhoea, it may not be the best option when there are antisocial behaviours related to menstruation (eg, hiding used sanitary products).

The first choice of pill would usually be the same as for any young woman requesting contraception, namely one with a mid-dose $(30 \mu \mathrm{g})$ of ethinylestradiol (EE) and a second-generation progestogen, for example, levonorgestrel (as in Microgynon $30 \circledR$ or equivalent). The formulation of the pill can then be tailored if necessary according to any side effects. Generally, there is a requirement to be able to swallow, but if a gastric feeding tube is in place, non-sugar coated pills (such as Loestrin $30 \AA$ ) may be crushed and introduced to the tube. ${ }^{3}$ Liaison with paediatricians 
and gastrostomy specialists is advised before starting this regimen.

Combined hormonal methods have more medical contraindications than other methods, particularly in view of increased venous thromboembolism (VTE) risk and risks related to immobility, elevated BMI, hepatic and cardiac conditions. ${ }^{13}$ Also, medications which induce hepatic enzymes (eg, carbamazepine) increase the metabolism and clearance of oral contraceptives. This is not such an important consideration when contraception is not desired, but may contribute to problems such as breakthrough bleeding. The specific interaction between COC and lamotrigine may be a relevant concern as there may be an increase in seizure frequency when used concurrently (especially if the conventional 21 days of pill taking followed by a 7-day break is followed). ${ }^{15}$ As discussed above, the UK Medical Eligibility Criteria apply to contraceptive use, and expert judgement is needed when considering the use of combined methods for gynaecological use.

\section{Combined transdermal patch}

The only combined transdermal patch (CTP) currently available in the UK, Evra ${ }^{\circledR}$, contains $600 \mu \mathrm{g}$ EE and $6 \mathrm{mg}$ norelgestromin (NGMN) releasing $33.9 \mu \mathrm{g}$ EE and $203 \mu \mathrm{g}$ NGMN every 24 hours. It can be used sequentially or in a tailored manner as for the COC. The systemic contraindications are the same as for COC, and some studies have suggested a slightly higher VTE risk, ${ }^{16}$ but the evidence is conflicting. The CTP has the advantage of weekly rather than daily administration by the patient or carers, swallowing is not required and there are no issues when using in women with malabsorption syndromes. Young women with disabilities may have a tendency to want to remove or scratch at the patch. This can be avoided by advising carers to apply the patch to the scapular area or central back, which is more difficult to reach.

The patch avoids first-pass metabolism and this may account for the fact that there is a slightly higher chance of systemic side effects than with the COC (eg, breast tenderness, nausea). ${ }^{17}$ There is the potential for skin irritation to develop but it is easy to remove the patch from the skin. If a patient develops side effects, has a very low BMI or is using enzyme-inhibiting drugs, it is possible to cut up the patch - this is not an 'exact science' and so should not be undertaken if the patch is being used for contraception. A new lowerdose patch, Lisvy ${ }^{\circledR}$, containing $550 \mu \mathrm{g}$ EE and $2.1 \mathrm{mg}$ gestodene releasing $13 \mu \mathrm{g} \mathrm{EE}$ and $60 \mu \mathrm{g}$ gestodene every 24 hours is awaiting approval. ${ }^{18}$ This is equivalent to a $20 \mu \mathrm{g}$ EE pill whereas Evra is equivalent to a $35 \mu \mathrm{g}$ pill. The patch is smaller, round and transparent, which may have additional advantages for placement as well as the advantage of lower risk of systemic side effects.
Progestogen-only pill

The progestogen-only pill (POP) has the advantage of having fewer medical contraindications than the combined pill, however it is not nearly as effective at providing cycle control. ${ }^{19}$ If there are difficulties with swallowing, the same considerations as for COC apply. As the desogestrel-containing POP inhibits ovulation, there is more likelihood of amenorrhoea. This means it is usually preferred to the conventional POP (eg, 350 $\mu \mathrm{g}$ norethisterone) for gynaecological benefits. The best menstrual outcomes are achieved when the pill is taken as close to the same time every day as possible. ${ }^{12}$

\section{Subdermal implant}

The etonogestrel-releasing contraceptive implant (available in the UK as Nexplanon ${ }^{\circledR}$ ) may cause erratic bleeding, with only 20\% users becoming amenorrhoeic. ${ }^{20}$ Despite the fact that that the implant cannot be relied on for amenorrhoea, it can often be helpful in stabilising cyclical mood disturbance, as it releases etonogestrel at a constant low dose and inhibits ovulation. Anecdotally, light spotting bleeding may be easier to manage than the demands of heavy periods and associated sanitary requirements. The implant lasts for 3 years and so avoids compliance issues, other than for the initial insertion. There is still ovarian follicular activity so estrogen levels remain normal and the implant does not therefore impair bone development.

Often it is parental consent which is employed (rather than patient consent due to capacity issues) when fitting an implant in a young woman with learning difficulties. The aim is to fit the implant as quickly as possible, with minimal distress, at a site relatively inaccessible for the patient. This is because she may pick at the insertion site, increasing the risk of infection, and also may try to bend and manipulate the implant, which may cause it to break. The technique used by an author (JD) is to settle the patient (eg, sitting on a parent's lap or with a parent standing round them to hold their arms still). Ethyl chloride spray (eg, Cryogesic $\left.{ }^{\circledR}\right)$ rather than local anaesthetic injection, is used to rapidly anaesthetise the skin. ${ }^{21}$ The implant is then fitted to the external aspect (usually over the triceps) of the dominant rather than the non-dominant arm. Another option would be to pre-prepare the site with anaesthetic cream (eg, Emla $\left.{ }^{\circledR}\right)$. A bandage is applied until the insertion site is fully healed. Replacement is more difficult, but if required the expired implant can be left in place and a new one simply added, preferably in the other arm to distinguish the two.

\section{Progestogen-only injectable}

Depot progestogen (medroxyprogesterone acetate $150 \mathrm{mg} / \mathrm{mL}$ ) is one of the most effective approaches for inducing amenorrhoea, with at least $70 \%$ of users achieving amenorrhoea at 1 year. ${ }^{22}$ It is available as intramuscular (Depo-Provera ${ }^{\circledR}$ ) and subcutaneous (Sayana Press ${ }^{\circledR}$ ) preparations. The injection needs to 
be given every 13 weeks and the subcutaneous preparation has the advantage that it may be easier to administer. For example, if a patient is a wheelchair user, it is easier to access the anterior thigh rather than the buttock, and the subcutaneous version has a shorter needle with a smaller gauge, and so may be less traumatic. Also there is the option of self or parent/carer administration.

The main concern when choosing the progestogen-only injectable (POI) is the link with osteopenia. Adolescents have not achieved their peak bone mass, and those with disabilities may have other risk factors for osteoporosis, such as anticonvulsant or steroid use, immobility and low BMI. Specialist advice must therefore be sought. International guidance varies significantly on this topic ${ }^{10}$ but bone protection (eg, with $1300 \mathrm{mg}$ calcium plus $400 \mathrm{IU}$ vitamin D) and add-back estrogen (eg, $25 \mu \mathrm{g}$ estrogen patch) should be considered. Bone densitometry (DEXA) scanning at the onset of therapy and at 2-yearly intervals ${ }^{23} 24$ is also recommended. There may be weight gain in some users and this may further impair mobility if patients are already overweight. Weight gain can be difficult to reverse and patients and carers should be warned that other unwanted side effects may take some months to wear off.

\section{Intrauterine system}

The intrauterine system (IUS) (Mirena ${ }^{\circledR}$ ) is well recognised for its gynaecological benefits. It is licensed for 5 years but its effects may continue for longer than this. (Levosert@ is an identical formulation but is only licensed for 3 years and only for contraception.) There is reduction in dysmenorrhoea and heavy bleeding, and amenorrhoea may develop. There is no interaction with other medications and there are no issues related to absorption. However, the insertion process means that there may be major considerations in this group of young women. To be inserted in the normal clinic environment, there needs to be reasonable mobility and consent to the procedure. It may be necessary to perform transvaginal ultrasound prior to insertion, as a minimal uterine cavity depth of $5-6 \mathrm{~cm}$ is necessary. ${ }^{25}$ A small case series of insertion in young women with disabilities $^{26}$ showed significant therapeutic benefit for $12 / 14$ participants, with the majority opting to continue for the 5 -year duration of the device. In these cases a brief general anaesthetic (GA) was required for insertion. If insertion under GA is planned, clinicians must remember that this may well be required for removal and should be available urgently in case of severe pain.

Many young women, however, are able to have intrauterine contraception fitted in a routine clinic environment and neither being young nor nulliparous is a contraindication to intrauterine contraceptive insertion. ${ }^{13}$ Another option that may be considered is the low-dose IUS (Jaydess ${ }^{\circledR}$ ), which has a narrower insertion tube and has been shown to improve dysmenorrhoea. A recent Phase III single-arm study of 304 postmenarcheal adolescent participants confirmed safety and efficacy in this group. ${ }^{27}$ Jaydess is not licensed for the management of HMB but anecdotally may be helpful.

\section{LEGAL AND ETHICAL ISSUES: CONSENT, CHILD SEXUAL EXPLOITATION AND ABUSE}

Approximately $30 \%$ of young people have sexual intercourse before the age of 16 years, the legal age of consent in the UK. ${ }^{28}$ A large US survey undertaken in schools showed no differences between adolescents with and without chronic conditions in the proportion ever having intercourse or age of sexual debut. ${ }^{1}$ There were no differences evident among girls with visible compared with invisible conditions; however, a significantly greater proportion of girls with invisible conditions than controls reported a history of sexual abuse.

Adolescents with learning or physical disabilities are particularly vulnerable to exploitation and may have further additional risk factors such as living in care, mental health problems, addictions, lack of support networks (eg, family/friends) and a past history of abuse or exploitation. ${ }^{29}$ If at all possible the young woman should be given the opportunity to have a confidential consultation, but this may not be possible or may need considerable preparation and dedicated time. Her concerns about sexual activity, fertility and body image will take time to explore.

Sexual abuse should also be considered in many gynaecological presentations (eg, genital soreness, genitourinary injuries, vaginal discharge, recurrent dysuria, STIs and pregnancy). Additionally there are non-gynaecological symptoms where abuse should be considered (eg, faecal soiling, rectal bleeding, enuresis and generalised abdominal pain). A young person's behaviour may change to indicate distress or anxiety (eg, self-harm or eating disorders) or there may be inappropriate sexualised behaviour when abuse has occurred. Where there are any concerns, local safeguarding processes must be implemented.

With regard to treatment, if the girl is assessed to lack Fraser competence and cannot understand what is proposed, then any action must be in her best interests. The requirement for interventions should be the least restrictive of basic rights, and those with parental responsibility have the legal right to give consent on behalf of minors for medical treatment. Legal advice may be required if a parent refuses to consent to a procedure that doctors believe to be in the child's best interests. The Mental Capacity Act 2005 provides the legal framework to protect vulnerable girls aged over 16 years who lack capacity.

\section{CONCLUSIONS}

The use of contraception in adolescents with disabilities is complex, reflecting the wide range of symptoms 
and circumstances of individual patients and a lack of applicable, evidence-based guidance. However, the scope for effective use of contraception in this group, both for effective prevention of unwanted pregnancy and the treatment of gynaecological conditions, is huge and can be genuinely life-changing for patients and their carers. Use of multidisciplinary teams (including general practitioners, appropriate clinical specialists, therapists and social workers) is key. The aims should be to provide reassurance and practical support in the context of normal menarche, to recognise and address concerns, and communicate, implement and monitor management options effectively. Tailored information and discussions on sex and relationships can be helpful, and robust capacity and safeguarding assessments are always necessary.

Contributors JD is the lead author. AT undertook the literature search and all three authors contributed to the development and authorship of the article.

Competing interests None declared.

Provenance and peer review Commissioned; externally peer reviewed.

(C) Article author(s) (or their employer(s) unless otherwise stated in the text of the article) 2018. All rights reserved. No commercial use is permitted unless otherwise expressly granted.

\section{REFERENCES}

1 Surís JC, Resnick MD, Cassuto N, et al. Sexual behavior of adolescents with chronic disease and disability. J Adolesc Health 1996;19:124-31.

2 Dickson J. Management of children and adolescents with gynaecological problems in primary care. In: Britton A, Connolly A, Women's Health in Primary Care. Cambridge, UK: Cambridge University Press, 2017.

3 Quint EH, O’Brien RF. Committee On Adolescence North American Society for Pediatric and Adolescent GynecologyNorth American Society for Pediatric and Adolescent Gynecology. Menstrual management for adolescents with disabilities. Pediatrics 2016;138:e20160295.

4 American College of Obstetricians and Gynecologists. Menstruation in Girls and Adolescents: Using the Menstrual Cycle as a Vital Sign (Committee Opinion No. 651). Obstet Gynecol 2015;126:e143-6.

5 Michala L, Creighton S. Adolescent gynaecology obstetrics. Gynaecol Reprod Med 2014;24:74-9.

6 Grover SR. Gynaecological issues in adolescents with disability. J Paediatr Child Health 2011;47:610-3.

7 Zacharin MR. Puberty, contraception, and hormonal management for young people with disabilities. Clin Pediatr 2009;48:149-55.

8 Albanese A, Hopper NW. Suppression of menstruation in adolescents with severe learning disabilities. Arch Dis Child 2007;92:629-32.

9 Case AM, Reid RL. Effects of the menstrual cycle on medical disorders. Arch Intern Med 1998;158:1405-12.

10 Quint EH. The conservative management of abnormal bleeding in teenagers with developmental disabilities. J Pediatr Adolesc Gynecol 2003;16:54-6.
11 Jeffery E, Kayani S, Garden A. Management of menstrual problems in adolescents with learning and physical disabilities. The Obstetrician of Gynaecologist 2013;15:106-12.

12 American College of Obstetricians and Gynecologists. Menstrual Manipulation for Adolescents with Physical and Developmental Disabilities. 2016. (Committee Opinion No. 668) https://www.acog.org/Resources-And-Publications/ Committee-Opinions/Committee-on-Adolescent-Health-Care/ Menstrual-Manipulation-for-Adolescents-With-Physical-andDevelopmental-Disabilities (accessed 24 Jan 2017).

13 Faculty of Sexual \& Reproductive Healthcare. UK Medical Eligibility Criteria for Contraceptive Use (UKMEC). 2016 https://www.fsrh.org/standards-and-guidance/uk-medicaleligibility-criteria-for-contraceptive-use-ukmec/ (accessed 24 Jan 2017).

14 Edelman A, Micks E, Gallo MF, et al. Continuous or extended cycle vs. cyclic use of combined hormonal contraceptives for contraception. Cochrane Database Syst Rev 2014;7:CD004695.

15 Sabers A, Buchholt JM, Uldall P, et al. Lamotrigine plasma levels reduced by oral contraceptives. Epilepsy Res 2001;47:151-4.

16 Faculty of Sexual \& Reproductive Healthcare. Combined hormonal contraception. 2012 https://www.fsrh.org/standardsand-guidance/documents/combined-hormonal-contraception/ (accessed 24 Jan 2017).

17 Lopez L, Grimes D, Gallo M, et al. Skin patch and vaginal ring versus combined oral contraceptive for contraception. Cochrane Database Syst Rev 2010;3:CD003552.

18 Health Products Regulatory Authority. Lisvy summary of product characteristics. http:/www.hpra.ie/img/ uploaded/swedocuments/LicenseSPC_PA1330-019-001_ 22072015155042.pdf (accessed 24 Jan 2017).

19 Clinical Effectiveness Unit FSRH. Progestogen-only Pills. 2015 https://www.fsrh.org/standards-and-guidance/documents/cecceu-guidance-pop-mar-2015/ (accessed 24 Jan 2017).

20 Faculty of Sexual \& Reproductive Healthcare. Progestogenonly Implants. 2014 https://www.fsrh.org/standards-andguidance/documents/cec-ceu-guidance-implants-feb-2014/ (accessed 24 Jan 2017).

21 Shefras J, Forsythe A, Nathani F, et al. An alternative method of anaesthesia for implant insertion: description of a clinical initiative in contraceptive care. J Fam Plann Reprod Health Care 2014;40:226-8.

22 Faculty of Sexual \& Reproductive Healthcare. Progestogenonly injectable contraception. 2014 https://www.fsrh.org/ standards-and-guidance/documents/cec-ceu-guidanceinjectables-dec-2014/ (accessed 24 Jan 2017).

23 Lee DJ. Care of patients using progestogen-only injectables. $J$ Fam Plann Reprod Health Care 2017;43:67-9.

24 Bonny AE, Harkness LS, Cromer BA. Depot medroxyprogesterone acetate: implications for weight status and bone mineral density in the adolescent female. Adolesc Med Clin 2005;16:569-84.

25 Bayer Mirena. Important safety information about mirena. http://hcp.mirena-us.com/placement-and-removal/preciseplacement.php (accessed 24 Jan 2017).

26 Pillai M, O'Brien K, Hill E. The levonorgestrel intrauterine system (Mirena) for the treatment of menstrual problems in adolescents with medical disorders, or physical or learning disabilities. BJOG 2010;117:216-21.

27 Gemzell-Danielsson K, Buhling KJ, Dermout SM, et al. A Phase III, single-arm study of LNG-IUS 8, a low-dose 
levonorgestrel intrauterine contraceptive system (total content $13.5 \mathrm{mg}$ ) in postmenarcheal adolescents. Contraception 2016;93:507-12.

28 The third national survey of sexual attitudes and lifestyles. The Lancet 2013;382:1757-856.
29 Rogstad K, Johnston G. Spotting the Signs. A national proforma for identifying risk of child sexual exploitation in sexual health services. 2014 https://www.bashh.org/documents/ Spotting-the-signs-A\%20national\%20proforma\%20Apr2014. pdf (accessed 24 Jan 2017). 